2016-2

\title{
Evaluating a Microbial Water Quality Prediction Model for Beach Management Under the Revised EU Bathing Water Directive
}

\author{
Zeinab Bedri \\ Technological University Dublin, zeinab.bedri@tudublin.ie \\ Aisling Corkery \\ University College Dublin \\ John O'Sullivan \\ University College Dublin, jj.osullivan@ucd.ie
}

See next page for additional authors

Follow this and additional works at: https://arrow.tudublin.ie/engschcivart

Part of the Civil Engineering Commons, and the Environmental Engineering Commons

\section{Recommended Citation}

Bedri, Z. et al. (2015) Evaluating a Microbial Water Quality Prediction Model for Beach Management Under the Revised EU Bathing Water Directive, Journal of Environmental Management, Vol. 167, pp 49-58.

https://doi.org/10.1016/j.jenvman.2015.10.046

This Article is brought to you for free and open access by the School of Civil and Structural Engineering at ARROW@TU Dublin. It has been accepted for inclusion in Articles by an authorized administrator of ARROW@TU Dublin. For more information, please contact arrow.admin@tudublin.ie, aisling.coyne@tudublin.ie, gerard.connolly@tudublin.ie.

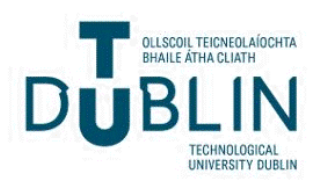




\section{Authors}

Zeinab Bedri, Aisling Corkery, John O'Sullivan, Louise Deering, Katalin Demeter, Wim Meijer, Gregory O'Hare, and Bartholomew Masterson 
Dublin Institute of Technology

ARROW@DIT

$2016-2$

\section{Evaluating a microbial water quality prediction model for beach management under the revised EU Bathing Water Directive}

Zeinab Bedri

Aisling Corkery

John O'Sullivan

Louise Deering

Katalin Demeter

See next page for additional authors

Follow this and additional works at: https://arrow.dit.ie/engschcivart

Part of the Civil Engineering Commons, and the Environmental Engineering Commons

This Article is brought to you for free and open access by the School of Civil and Structural Engineering at ARROW@DIT. It has been accepted for inclusion in Articles by an authorized administrator of ARROW@DIT.

For more information, please contact yvonne.desmond@dit.ie,

arrow.admin@dit.ie, brian.widdis@dit.ie. 
Authors

Zeinab Bedri, Aisling Corkery, John O'Sullivan, Louise Deering, Katalin Demeter, Wim Meijer, Gregory O'Hare, and Bartholomew Masterson 


\title{
Evaluating a microbial water quality prediction model for beach management under the revised
} EU Bathing Water Directive

Zeinab Bedri $^{\mathrm{a} *}$, Aisling Corkery ${ }^{\mathrm{a}}$, John J. O’Sullivan ${ }^{\mathrm{a}, \mathrm{d}}$, Louise A. Deering ${ }^{\mathrm{b}}$, Katalin Demeter ${ }^{\mathrm{b}}$, Wim G.Meijer $^{\mathrm{b}, \mathrm{d}}$, Gregory O'Hare ${ }^{\mathrm{c}, \mathrm{d}}$, and Bartholomew Masterson ${ }^{\mathrm{b}}$

a Centre for Water Resources Research, School of Civil, Structural, and Environmental Engineering, University College Dublin, Belfield, Dublin 4, Ireland

b School of Biomolecular and Biomedical Science, University College Dublin, Belfield, Dublin 4, Ireland

c Clarity Centre, UCD School of Computer Science and Informatics, University College Dublin, Belfield, Dublin 4, Ireland

d UCD Earth Institute, University College Dublin, Belfield, Dublin 4

* Corresponding author: Tel. +353 1 716 3228, Fax: +353 1 7163297, E-mail: zeinab.bedri@ucd.ie

\begin{abstract}
The revised Bathing Water Directive (2006/7/EC) requires EU member states to minimise the risk to public health from faecal pollution at bathing waters through improved monitoring and management approaches. While increasingly sophisticated measurement methods (such as microbial source tracking) assist in the management of bathing water resources, the use of deterministic predictive models for this purpose, while having the potential to provide decision making support, remains less common.
\end{abstract}

This study explores an integrated, deterministic catchment-coastal hydro-environmental model as a decision-making tool for beach management which, based on advance predictions of bathing water quality, can inform beach managers on appropriate management actions (to prohibit bathing or advise the public not to bathe) in the event of a poor water quality forecast. The model provides a 'moving window' five-day forecast of $E$. coli at a bathing water compliance point off the Irish coast and the accuracy of bathing water management decisions were investigated for model predictions under two scenarios over the period from the $11^{\text {th }}$ August to the $5^{\text {th }}$ September, 2012. Decisions for Scenario 1 were based on model predictions where rainfall forecasts from a meteorological source (www.yr.no) were used to drive the rainfall-runoff processes in the catchment component of the model, and for Scenario 2, were based on predictions that were improved by incorporating real-time rainfall data 
from a sensor network within the catchment into the forecasted meteorological input data. The accuracy of the model in the decision-making process was assessed using the contingency table and its metrics.

The predictive model gave reasonable outputs to support appropriate decision making for public health protection. Scenario 1 provided real-time predictions that, on $77 \%$ of instances during the study period where both predicted and $E$. coli concentrations were available, would correctly inform a beach manager to either take action to mitigate for poor bathing water quality or take no action. However, Scenario 1 also provided data to support a decision to take action (when none was necessary - a type I error) in $4 \%$ of instances and to take no action (when action was required - a type II error) in 19\% of the instances analysed. Type II errors are critical in terms of public health protection given that for this error, bathers can be exposed to risks from poor bathing water quality. Scenario 2, on the other hand, provided predictions that would support correct management actions for $79 \%$ of the instances but would result in type I and type II errors for $4 \%$ and $17 \%$ of the instances respectively.

Comparison of Scenarios 1 and 2 for this study indicate that Scenario 2 gave a marginally better overall performance in terms of supporting correct management decisions, as it provided data that could result in a lower occurrence of the more critical type II errors.

Given that the 28 member states of the European Union are required to engage with the public health provisions of the revised Bathing Water Directive, issues of compliance, pertaining particularly to the management of bathing water resources, remain topical. Decision supports for managing bathing waters in the context of the Directive are likely to become the focus of much attention and although, the current study has been validated in bathing waters off the east coast of Ireland, the approach of using a deterministic and integrated catchment-coastal model for such purposes is easily transferable to other bathing water jurisdictions.

Keywords: Faecal indicator bacteria (FIB); prediction; bathing water quality management; coastal and catchment modelling; revised EU Bathing Water Directive

\section{Introduction}

Coastal waters have long been recognised for their recreational and social benefits to communities within Europe and elsewhere. Safe participation in water-based recreational activities relies heavily on the water quality of these waters as there is considerable epidemiological evidence in the literature 
(for example Fleisher et al., 1996; Haile et al., 1999; Wade et al., 2008) that confirms that contact with faecal-contaminated recreational waters poses serious health risks to bathers.

In Europe, the quality of coastal recreational waters is safe-guarded by the European Union (EU) Bathing Water Directives 76/160/EEC (CEC, 1976) and 2006/7/EC (EC, 2006) which has as its goal the protection of public health and the environment from faecal pollution in bathing waters.

The Bathing Water Directive 2006/7/EC (referred to hereafter as the revised Bathing Water Directive) was adopted in 2006, and will fully replace Directive 76/160/EEC in December 2015 to place a stronger emphasis on the protection of public health in bathing waters through improved monitoring and management approaches (EC, 2006). It specifies tighter microbiological standards that use more reliable faecal indicator bacterial (FIB) parameters, namely intestinal enterococci (IE) and Escherichia coli (E. coli) for predicting microbiological health risk associated with bathing in marine and fresh waters. The revised Directive requires beach managers to predict in advance, the exceedence of IE and E. coli concentrations of the threshold levels set in the revised Directive (see Table 1), take the necessary management actions to restrict their occurrence (if possible) and reduce the health risk by warning and informing of the public. This increased provision of public information is intended to allow beach users to make an informed choice on whether to use the bathing water at any particular time (Stidson et al., 2012).

\section{Table 1 here}

However, the revised Directive recognises that elevated levels of FIB in bathing waters may occur naturally from rainfall-related runoff in agricultural catchments and allows for a temporary relaxation of the standards during short-term pollution incidents, where up to $15 \%$ of samples can be disregarded or 'discounted' from the 4-year water quality record used to assess compliance. However, the provision of discounting samples is only permitted at bathing sites where a beach manager can demonstrate adequate knowledge of the environmental system affecting the bathing water quality, predict in advance the occurrence of short-term pollution events, and prohibit bathing or issue 'advisory' notices to enable the public make an 'informed choice' with regard to bathing. Although a recently adopted position for member states (ETC, 2012) allows for a somewhat intuitive approach to the predictability of short-term pollution, in which prior knowledge of factors or hazards that trigger microbial contamination of bathing waters is recognised, more robust strategies may benefit from predictive modelling tools to help understand the environmental processes affecting the coastal water quality and to provide advance predictions of known accuracy of the bathing water quality for the protection of public health.

The principle of beach water quality management using a predictive modelling approach was first suggested by the World Health Organisation (WHO, 2003) as a rapid and inexpensive tool for 
providing information to the public. This has largely contributed to the increasing popularity of predictive water quality models as tools for beach water quality management in Hong Kong and the US. Thoe et al. (2012) developed two data-driven models; multiple linear regression (MLR) and artificial neural network (ANN) to correlate FIB levels with a number of hydro-environmental factors (rainfall, solar radiation, wind speed, tide level, etc.) at four beaches in Hong Kong. MLR models have been also successfully applied as beach management tools in many parts of the US (see for examples USEPA, 2010b, Thoe et al., 2014; Frick et al., 2008; Francy, 2009; Olyphant and Whitman, 2004; Nevers and Whitman, 2005). ANN approaches have also been widely used in the US for beach water quality management (see for examples He and He, 2008; Zhang et al., 2012; Thoe et al., 2014). Categorical models such as decision trees were applied in some studies (see for examples Parkhurst et al., 2005; Bae et al., 2010). The results of these modelling studies indicate that predictive models have generally out-performed traditional beach monitoring methods to capture beach pollution as beach monitoring relies only on outdated/previous-day measurements of FIB (Frick et al., 2008; Nevers and Whitman, 2011; Hou et al., 2006). While reasonable results are reported in the literature using the above MLR, ANN, and decision tree approaches, the performance of such-data driven approaches will continue to be questionable if they are utilised to extrapolate water quality predictions outside the range of data that was used in their development and training ( see USEPA, 2010a).

The use of predictive models as decision support tools for managing bathing waters in the context of the revised EU Bathing Water Directive are likely to become the focus of much attention. Of the few available such models in Europe, McPhail and Stidson (2009) developed an Excel spreadsheet-based water quality prediction tool for 10 bathing sites in Scotland. The tool uses antecedent rainfall data and subsequent river flow to predict FIB levels at these beaches. In a later study, Stidson et al. (2012) developed the tool further into a decision tree approach to categorise the available hydroenvironmental variables and provide a 'family tree' style view of the relationships between variables. Bathing water quality predictions of both Scottish approaches are communicated to the public via an Electronic Signage Post system at the concerned beaches.

In Ireland, an Excel-based regional prediction model similar to that of McPhail and Stidson (2009) has been developed for the 63 of the 136 coastal and inland bathing waters that needed it. The model also uses hydro-environmental variables (e.g. antecedent rainfall and river flow) to predict FIB levels at these bathing sites. While preliminary results of this model indicate satisfactory FIB predictions at many of these bathing sites, the model failed to perform at sites in more complex environmental settings. This is due to the fact that data-driven models do not represent the physical processes/ changes affecting the environmental system and therefore such models can be of limited use in catchment-coastal systems subjected to systemic changes in background pollution levels. 
Therefore, priority for the provision of bathing water quality predictions in these more complex settings should be given to the use of deterministic predictive models that are based on knowledge of the physical properties of the coastal environmental system. The development of one such model that comprises an integrated, deterministic catchment-coastal model for both real-time and short-term predictions of coastal water quality is described in Bedri et al. (2014).

This study explores the potential use of this deterministic integrated catchment-coastal prediction model as a decision-support tool to assist beach managers in the issuing of public warnings as required by the revised Bathing Water Directive (2006/7/EC). The model has the advantage of providing water quality predictions well in advance of the occurrence of elevated FIB levels and this can inform beach managers in the decision making process on whether to prohibit bathing or advise the public not to bathe. The study also assesses the efficacy of the prediction model in minimising the 'errors' in beach management decisions. Such errors occur when the concentrations of predicted FIB are not equal to the actual concentrations and may result in either inadvertent exposure of the public to high concentrations of FIB or the unnecessary exclusion of swimmers from bathing waters that meet acceptable standards of Directive 2006/7/EC. Notably, the Irish Health Service Executive (HSE) has required regulations to be set to cater for the public health when excessively high levels of indicator organisms are found at designated bathing waters in Ireland (EPA, 2013). Although, the revised Bathing Water Directive defines water quality in terms of two FIB, namely E. coli and IE, E. coli is the predicted parameter adopted in this study.

The paper is divided into four sections. Section 2 presents the study area, the Dargle Bray catchment coastal system and briefly describes the structure of the prediction tool and its components. The ap

plication of the prediction tool to the study area, and the scenarios tested are also presented. The findings of the numerical experiments and their significance are discussed in Sections 3 and 4 and following this, Section 5 summarises the conclusions of the study.

\section{Materials and Methods}

\subsection{Study site}

Bray beach is a seaside resort located on the east coast of Ireland (Longitude $6.10^{\circ} \mathrm{W}$, Latitude $53.22^{\circ} \mathrm{N}$ ) and is a designated European Union (EU) bathing site (see Figure 1). The beach, approximately $1.5 \mathrm{~km}$ long and $0.5 \mathrm{~km}^{2}$ in area, is a common recreational destination for an average of 500 visitors per day during the Irish bathing season (June - September). The beach is considered shallow and falls gradually in the seaward direction (to the East) from the low water mark to a depth of $8 \mathrm{~m}$, after which it slopes more steeply to reach depths from 20 to $25 \mathrm{~m}$ at a distance approximately 
$2 \mathrm{~km}$ offshore. Tides, which are semi-diurnal, are the main forces driving the dynamics of the coastal waters. These run north on a flood tide and south on an ebb tide, roughly parallel to the coastline. Tides in the region vary between $4.1 \mathrm{~m}$ and $0.7 \mathrm{~m}$ (above chart datum) for mean high water and mean low water spring tides respectively, and between $3.4 \mathrm{~m}$ and $1.5 \mathrm{~m}$ (above chart datum) for mean high water and mean low water neap tides (Mansfield, 1992).

The Dargle River forms the main freshwater inflow into the coastal waters of Bray beach. The river has an average dry weather flow of $3 \mathrm{~m}^{3} / \mathrm{s}$ which can rise rapidly to $300 \mathrm{~m}^{3} / \mathrm{s}$ during extreme flood events. The Dargle River is relatively short (20 km in length) but has a steep slope of approximately $2.7 \%$. The river together with its tributary network drains a contributing catchment of circa $133 \mathrm{~km}^{2}$ and flows into the Irish Sea at Bray Harbour which is just north of Bray beach (see Figure 1). The Dargle catchment, although small, is comprised of urban areas in the lower coastal zone of the catchment, but this differs from a more diverse land-use mix of the upper catchment which includes tillage, pasture/sheep farming, forestry and peat boglands (Bruen et al., 2001).

\section{Figure 1 here}

The 30-year rainfall record to the present date, obtained from the Irish meteorological service (Met Éireann, www.met.ie), indicates that the mean annual rainfall in Bray is circa. $800 \mathrm{~mm} /$ year with over a third of the annual rainfall occurring during the Irish bathing season (June - September). In addition, long-term rainfall records show that the months of June and August exhibit the greatest daily totals. This, together with the relatively steep slope of the catchment topography, is of particular concern to the bathing water managers of Bray beach as intense rainfall events in the upland Dargle catchment can produce runoff that is a source of episodic short-term pollution incidents in the near-shore coastal waters of the beach.

\subsection{Description of the prediction tool}

The current study uses the real-time water quality prediction tool developed in Bedri et al. (2014). The prediction tool comprises an integrated catchment-coastal model to simulate flow and contaminant transport from the catchment into marine waters. The integrated model utilises three DHI software; the NAM rainfall-runoff model (DHI, 2013a), river flow and water quality model MIKE11 (DHI, 2013a), and the three-dimensional, flexible mesh coastal model MIKE3 FM (DHI, 2013b). The models, interfaced to the core of the prediction tool, run sequentially, i.e., in the form of a cascade with the forcing of each downstream model being the result of the model upstream of it (see Figure 1 in Bedri et al., 2014)(Figure 2). Rainfall is the main driver of the hydrological processes in NAM (which is the first model in the cascade) and is drawn from two sources: (i) the Norwegian 
meteorological source (www.yr.no) which delivers rainfall forecasts for up to 10 days in advance, and (ii) real-time data, when available, to be used by the NAM model to improve predictions of the water quality variables. Using rainfall (forecasted and/ or measured) to drive the rainfall-runoff processes in NAM, the model produces flow at the sub-catchment outlets which serve as inputs into the MIKE11 model which routes the flow and water quality variables in the river network to the coastal waters. Finally, the MIKE3 FM coastal model uses flow and water quality outputs from MIKE11, together with tidal and meteorological forcings, to simulate the current flow, transport and fate of water quality variables ( $E$. coli in the current study) in the marine environment.

The prediction tool incorporates a Microsoft SQL server database management system for the handling and management of the predicted and real-time data both used and generated by the prediction tool. The database is also the primary tool for archiving and backing-up these data sets.

\section{Figure 2 here}

During the operation of the prediction tool, the integrated model is run to produce water quality predictions for a specified forecasting period $\left(\mathrm{T}_{\text {for }}\right)$ using rainfall forecasts from the meteorological website (www.yr.no) to drive the model. The forecasts are routinely updated every $\mathrm{T}_{\text {up }}$ hours in which real-time rainfall observations of the last $\mathrm{T}_{\text {up }}$ hours are used to improve the predictions of the water quality variables. Therefore each model execution is conducted for the period $\left(T_{u p}+T_{\text {for }}\right)$ to include both the updated and forecasted rainfall information. The prediction tool thus operates in a sliding window fashion with the window size being the routine update period $\left(\mathrm{T}_{\mathrm{up}}\right)$. For the simulations of the coastal modelling component using MIKE3 FM, the simulation period $\left(\mathrm{T}_{\text {up }}+\mathrm{T}_{\text {for }}\right)$ is discretised into time-packets of duration $\left(\mathrm{T}_{\mathrm{m}}\right)$ to facilitate the production of intermediate results files (time- and spacevarying hydrodynamic and water quality variables over the simulation period $\mathrm{T}_{\mathrm{m}}$ ). This was necessary to allow intervention in the model execution to incorporate real-time observations without loss of completed predictions. This mechanism for active merging of real-time rainfall information is enabled by a routine scheduler that triggers the execution of emergency updates when a user-defined difference in value (or threshold) between observed and forecasted rainfall amounts is detected. In such cases, the model execution is halted and repeated to include updates in the observed rainfall information.

\subsection{Application of the prediction tool}

\subsubsection{Data Requirements}

An extensive data set was required for the set-up and calibration of the catchment and coastal modelling components of the prediction tool and its application to the Dargle-Bray system (see Bedri 
et al., 2014). Data was also needed to support the tests conducted for the study that is the focus of this paper. These consisted of:

(i) Weather forecasts: the weather forecasts that form inputs to the catchment model for the operation of the prediction tool were extracted from www.yr.no, a joint online weather service maintained by the Norwegian Meteorological Institute and the Norwegian Broadcasting Corporation. The data comprises precipitation, air temperatures, wind speeds and directions. Scripts were coded in order to automate the access of the forecasts from the web source, conduct automatic checks for the coherence of forecasts, fill any gaps with linearly interpolated data, extract the required weather variables and import them to the prediction tool.

(ii) Real-time weather and flow data within the Dargle catchment: this was obtained from an Environmental Wireless Sensor Network (EWSN) of automatic sensors for two weather stations measuring rainfall, air temperature and wind speed and direction, six rain gauges and eight river stations comprising water level recorders and temperature sensors (Figure 1). This EWSN adopts a centralised topology to automate the continuous collection of data remotely, and to transmit the sensed data to a database via a General Packet Radio Service (GPRS) connection.

(iii) Water quality data at Bray beach: this consisted of enumerations of E. coli taken at the bathing water compliance point at Bray beach on five days between $11^{\text {th }}$ August and $5^{\text {th }}$ September, 2012. These were hourly samples taken at a depth of $0.5 \mathrm{~m}$ below the water surface throughout the duration of a tidal cycle (approximately 12 hours). Such a sampling strategy was essential in order to capture the tidal variations of the bacterial levels at Bray Beach and the sampling dates were selected according to tidal conditions (spring, mean and neap tides) in the Bray coastal zone. The number of samples collected over the five sampling days wasere 52 (average of circa 10 samples per sampling day). The E. coli enumerations covered the full range of tidal cycles (spring, mean and neap tides) in the Bray coastal zone. Once collected from the water surface, the water quality samples were stored in 1litre bottles and preserved in ice-packed containers until they had been analysed for E. coli. Microbial enumeration commenced within 24 hours of the sample being taken using the membrane filtration method (ISO, 2000).

\subsubsection{Application}

The simulations in the current study explore the suitability of the water quality prediction tool developed by Bedri et al. (2014) as a beach management tool to inform bathing water managers whether to prohibit bathing or advise the public not to bathe. In so doing, the study assesses the efficacy of the tool in minimising the "errors" in beach management where the public are often either 
unknowingly swimming in contaminated beach water or are prohibited from/ or advised against swimming in water that meets the public health criteria.

Using the calibrated catchment-coastal model of the Dargle-Bray system, simulations were performed by the forecasting system to provide short-term and real-time predictions of $E$. coli concentrations at Bray beach. A short-term forecast period of five days was selected based on the length of the 'sampling window' reported in the revised Bathing Water Directive. The simulations covered the period from the $11^{\text {th }}$ August to the $5^{\text {th }}$ September, 2012 and the forecasts were updated every 12 hours in a sliding window fashion.

The initial/background conditions of the integrated model were established by initially running the catchment modelling component for a six-month period and the coastal component for a period of three days. Using the 'hot start' result files produced at the end of the initial conditions simulations, the prediction tool was run for a further initial period of three days (from 00:00 on the $8^{\text {th }}$ August to 00:00 on the $11^{\text {th }}$ August) before performing simulations for the required period (00:00 on the $11^{\text {th }}$ August to 00:00 on the $6^{\text {th }}$ September, 2012).

For the purpose of the current study, the prediction tool was used to simulate two scenarios:

(i) Forecasts only (Scenario 1): in which the prediction tool provides water quality predictions based on the forecasted sub-hourly rainfall amounts in the catchment obtained from the meteorological website www.yr.no. A scheduler coded within the forecasting system, checks the meteorological website for updates in rainfall forecasts and parses them to the database when available. The database is queried for updates of these forecasts every 12 hours and these updates replace the original weather forecast record in the subsequent update simulation, and;

(ii) Improved forecasts using real-time data (Scenario 2): in which the rainfall forecasts in Scenario 1 are improved by incorporating real-time rainfall data recorded by the Environmental Wireless Sensor Network (EWSN) deployed in the Dargle catchment (see Figure 1).

Over the course of the simulation, hourly queries are scheduled to check the database for updates of observed rainfall data. Emergency updates are scheduled to take place when a pre-defined accumulated difference is detected between the observed and forecasted rainfall amounts (defined in the current study as $10 \mathrm{~mm}$ over a six hour period). Otherwise, the observed rainfall information of the previous 12 hours is stored in the database until the time of the next scheduled update where it is augmented to the forecasted rainfall of the next forecasted period $\left(\mathrm{T}_{\text {for }}\right)$ in an advanced sliding window fashion. 


\subsection{Performance evaluation of the prediction tool}

The accuracy or success of the tool in predicting E. coli concentrations at Bray beach was assessed using two approaches: (i) evaluation of the fit between observed and predicted E. coli concentrations, and (ii) analysis of the contingency table and a number of key metrics derived from it (see Bennett et al., 2013; Manzato, 2007).

The observed E. coli concentrations at Bray beach taken between the $11^{\text {th }}$ August and $5^{\text {th }}$ September, 2012 were used for the assessment and analysis in the two approaches.

\subsubsection{Model fit}

For the evaluation of the fit between observed and predicted $E$. coli concentrations over the simulated period, two statistical criteria were utilised: the Root Mean Square of Errors - standard deviation ratio (RSR) developed by Moriasi et al. (2007), and the Willmott (1981) index of agreement $d$ :

$R S R=\frac{\sqrt{\sum_{i=1}^{n}(O-P)^{2}}}{\sqrt{\sum_{i=1}^{n}(O-\bar{O})^{2}}}$

$d=1-\frac{\sum|P-O|^{2}}{\sum(|P-\bar{O}|+|O-\bar{O}|)^{2}}$

where $P$ and $O$ in Equations (1) and (2) are the predicted and observed values for a simulated variable (E. coli concentrations) respectively and where $\bar{O}$ is the mean of the observed values.

The RSR metric standardises the Root Mean Square of Errors using the standard deviation of observed values thereby producing a normalisation factor which ranges from a value of 0 , indicating zero residual variation or a perfect model, to a large positive value. The index of agreement was developed by Willmott (1981) as a standardised measure of the degree of model prediction error and varies between 0 and 1 (Moriasi et al., 2007). Perfect agreement between model results and

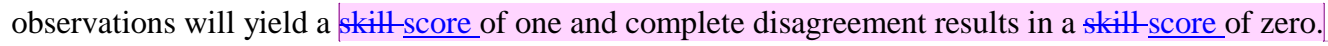

The statistical criteria were used to assess the fit between observed and predicted E. coli concentrations for Scenarios 1 and 2 on days D-2 (2-days in advance forecast of water quality) and D (same day forecast or the day in which water quality samples were taken at Bray beach), lead-in days in which accurate water quality predictions in the context of informing a beach management decision on Day D, are particularly significant.

2.4.2 Accuracy of prediction for decision support/beach management 
The contingency table and its metrics (see Tables 2 and 3) were employed to assess the accuracy of the model in predicting the compliance and or exceedence of the E. coli concentrations to the Sufficient E. coli standard values in the revised Bathing Water Directive (see Table 1) in order to support the beach management decisions at Bray.

Contingency tables were developed for $E$. coli to establish the number of occurrences where the model has correctly predicted: (i) the exceedence of the Sufficient standard values (referred to as hits in the contingency table), (ii) the occurrences of correct negatives in which both observed and predicted E. coli concentrations are below the standard value), (iii) the number of alarms missed by the model and (iv), the number of false alarms (Table 2). The lesser the occurrences of misses and false alarms, the more robust is the model as a bathing management tool. Therefore, an ideal model would have data only in the hits and correct negatives categories. Table 3 lists the metrics of the contingency table used in the current study, along with their limits and ideal values. These are the Accuracy, Hit Rate, False Alarm Rate, False Alarm Ratio and the Success Index. The contingency table and its metrics were computed for Scenarios 1 and 2 on days D-2 and D.

For the assessment of the efficacy of the prediction model in supporting the decision-making process for beach management, a 'binary approach' that is based on the contingency table was adopted in which beach managers either: (i) 'take action' by either prohibiting bathing or advising the public not to bathe, or (ii) 'take no action' or do nothing, depending on how E. coli concentrations compare to the Sufficient standard values of Directive 2006/7/EC (Table 2c). Errors in the decision-making process result in either inadvertent exposure of the public to high/unacceptable concentrations of faecal indicator bacteria (type II error in Table 2b) or the exclusion of swimmers from water that meets the exposure standard (type I error). More type II errors result in more swimmers being exposed to high concentrations of faecal indicator bacteria and therefore increased risk levels (Nevers and Whitman, 2011). On this basis, decreasing the occurrences of type II is of paramount importance for ensuring the protection of public health. Type I errors on the other hand would result in bathing prohibitions in waters that meet the standards of Directive 2006/7/EC, and while these may impact on the local economy of a bathing water area, they do not present a risk to public health (Table $2 \mathrm{~d}$ ).

Based on the contingency table and its metrics computed for model predictions of E. coli on days D-2 and $\mathrm{D}$, the management outcomes resulting from the predictions of Scenarios 1 and 2 were compared.

\section{Table 2 here}

Table 3 here

\section{Results}

3.1 Operation and speed 
All simulations were executed on an Intel Xeon, 64-bit, $2.4 \mathrm{GHz}$ machine. Simulations for five-day forecast periods of Scenario 1, which provides predictions based on forecasted rainfall only, took approximately 7.25 hours. The scheduled update for the forecasts was every 12 hours in the current study. This allowed the machine a down-time of approximately five hours before the commencement of a subsequent scheduled update for water quality forecasts. Simulations of Scenario 1 were completed for a period of 26 days $\left(11^{\text {th }}\right.$ August $-5^{\text {th }}$ September, 2012) with a total model run-time of approximately 15.4 days.

Simulations of Scenario 2 covered a period of 5.5 days at each scheduled update and comprised a 5day forecast (using forecasted rainfall amounts) together with a 12 hours hind-cast (using observed rainfall of the previous 12 hours obtained from the ESWN network within the Dargle catchment). Therefore, the corresponding simulations of Scenario 2 took a somewhat longer time than for Scenario 1 (eight hours), the additional time being required to execute the model re-runs necessary to incorporate real-time rainfall observations. The total model run-time taken by Scenario 2 to complete the 26-day simulation was approximately 17.1 days.

It is worth noting that the simulations of Scenario 2 in the period investigated did not include emergency updates since the rainfall totals accumulated over a 6 hour period did not exceed the threshold limit of $10 \mathrm{~mm}$ (as set in the current study) necessary to trigger emergency updates. The inclusion of emergency updates would have significantly increased the total model run-time since these would entail halting and repeating simulations to actively incorporate the 'new' information on rainfall.

\subsection{Performance of the prediction tool}

\subsubsection{Model fit}

Table 4 summarises the statistics of the two metrics, RSR and index of agreement $(d)$ used for the evaluation of the fit between observed and predicted $E$. coli concentrations on days D-2 (2 days in advance forecast of the water quality) and D (same day forecast, or the day in which water quality samples were taken at Bray beach).

Computed RSR values between measured and predicted E. coli concentrations for Scenarios 1 and 2 exhibited a $15 \%$ drop in values on day $\mathrm{D}$ in comparison to day D-2, demonstrating that simulations of day D give an improved fit to measured E. coli concentrations than simulations for day D-2. The RSR values for days D-2 and D also show that predictions of Scenario 2, the scenario with improved rainfall forecasts, has presented a better fit to observed E. coli concentrations than Scenario 1. 


\section{Table 4 here}

The index of agreement, $d$ (Table 4), between predicted and measured E. coli concentrations of Scenario 1 is shown to increase from 0.61 on day D- 2 to 0.66 on day D, again indicating a better fit between predicted and measured $E$. coli concentrations due to improved rainfall forecasts as the sampling day (D) approaches. The index of agreement for Scenario 2 has indicated a better agreement than Scenario 1 and was also shown to be improved from 0.62 on day D-2 to 0.67 on day D.

\subsubsection{Accuracy of prediction for decision support/beach management}

Table 5 shows the computed metrics of the contingency table for the predictions of Scenarios 1 and 2 on days D-2 and D. These assess the accuracy of the model in predicting the compliance and or exceedence of $E$. coli concentrations to the Sufficient $E$. coli standard values in the revised Bathing Water Directive. The results show that the accuracy of the predictions for Scenarios 1 and 2 on day D2 are similar at $77 \%$. This has increased to $79 \%$ for Scenario 2 on day D while it remained unchanged for Scenario 1. This indicates that predictions of Scenario 2 provide an improvement in the accuracy of predicted E. coli concentrations when compared to Scenario 1 . The results also indicate that the hit rate for Scenario 1 has dropped from 0.38 to 0.31 . This is reflected in Figure $2 \mathrm{a}$ by the percentage of the instances in which the beach was correctly closed on days D-2 and D (11\% and $9 \%$ of the instances respectively). For Scenario 2 the hit rate remains unchanged at 0.38 (11\% of the instances where the beach is correctly closed in Figure $2 \mathrm{~b}$ ). Also, the false alarm rate for both Scenarios 1 and 2 exhibit a decrease from 0.09 to 0.06 indicating an improvement in the predictions of both Scenarios from day D-2 to day D due to the drop in the occurrences of false alarms coupled with the increase in the occurrences of correct negatives (correct no action in Figure 2). Both Scenarios 1 and 2 have shown a decrease in values of false alarm ratio from day D-2 to day D by $13 \%$ and $24 \%$ for Scenarios 1 and 2 respectively. The success index has dropped for Scenario 1 but slightly increased in Scenario 2 indicating the superiority of Scenario 2 over Scenario 1 in predicting the compliance and exceedence occurrences of the Sufficient standard values of the revised Directive.

\section{Table 5 here}

Results in Table 5 indicate that Scenario 2 performed marginally better than Scenario 1 in predicting the compliance/ exceedence of E. coli concentrations to the Sufficient standard values of the Bathing Water Directive. In terms of the false alarm rate and false alarm ratio, both scenarios have shown a decrease from day D-2 to day D but the decrease in false alarm ratio is more significant for Scenario 2. 
Figures 2(a) and (b) compare the management outcomes resulting from the predictions of Scenarios 1 and 2 on forecasting days D-2 and D respectively. Scenarios 1 and 2 for E. coli on day D-2 are shown to exhibit a similar record of occurrences of hits, misses, correct negatives and false alarms resulting in similar management outcomes in which 'no action' was correctly taken for $66 \%$ of the predictions and 'action' was correctly taken for $11 \%$ of the predictions. Type I and type II errors on day D-2 were $6 \%$ and $17 \%$ respectively.

\section{Figure 2 here}

The results on day $\mathrm{D}$ show that the real-time component of the model has correctly predicted the compliance/ failures of Bray beach in meeting the Sufficient standard values of the revised Directive for $77 \%$ and $79 \%$ of the predictions for Scenarios 1 and 2 respectively (based on the combined 'correct no action taken' and 'correct action taken' categories). By extension, relying on predictions from the prediction tool to support the beach management decision making for the investigated period from the 11th August to the 5th Sep, 2012, would result in management decisions being correctly made between 77 and $79 \%$ of the time.

When compared to predictions on day D-2, those for day D of Scenario 1 (Figure 2a) potentially result in a $2 \%$ decrease in the number of occasions where an 'action' should be taken by managers of Bray beach together with an increase in the occurrences of type II errors from predictions on day D. This has potentially serious implications for the management of bathing waters under Directive 2006/7/EC as such errors indicate instances where exceedances to the Sufficient standard values of the Directive are missed (not predicted by the model) and may result in a risk exposure to the bathing public (see Table $2 \mathrm{~d}$ ) given that beach managers would not have been informed of the need to take measures to mitigate this risk.

Conversely, predictions on day D for Scenario 2 (Figure 2b) show no real change in the occurrences of hits (where an 'action' was correctly taken by managers) and also no change in the occurrences of type II errors. When compared to those on day D-2, predictions indicate a $2 \%$ decrease in the occurrences of type I errors and a $2 \%$ increase in the occurrences where 'no action' should be taken. The reduction in type I error reflects an improvement in the predictions for Scenario 2 on day $\mathrm{D}$ given that such errors misinform beach managers and potentially result in the taking of unnecessary actions (prohibition of bathing or the issuing of an advisory against bathing) in situations where bathing waters continue to meet the Sufficient standard values of the revised Directive.

In summary therefore, the deterministic predictive model in the current study has facilitated positive decision making in terms of public health protection. The real-time model has correctly predicted the compliance/ failures of Bray beach in meeting the Sufficient standard values of the revised Directive for $77 \%$ and $79 \%$ of the predictions for Scenarios 1 and 2 respectively (based on the combined 

'correct no action taken' and 'correct action taken' categories). Conversely, the real-time component has produced data that would unnecessarily prohibit bathing for $4 \%$ of the predictions (type 1 errors) and would unnecessarily expose bathers to public health risks from poor bathing water quality (type II errors) for $19 \%$ and $17 \%$ of the predictions for Scenarios 1 and 2 respectively.

The results of the study highlight the marginal superiority of Scenario 2, where real-time rainfall data is utilised to improve the water quality predictive capacity in the study area. Nevertheless, the reasonably accurate predictions of Scenario 1 indicate that the prediction tool can still produce acceptable predictions based on rainfall forecasts only and this is of particular note in the context of applying deterministic modelling approaches of the type presented for water quality prediction and decision making in other catchment-coastal systems with limited or no real-time rainfall data available.

While the results indicate a reasonable accuracy in $E$. coli prediction using the real-time prediction tool, inconsistencies between measured and predicted E. coli concentrations may still occur due to model accuracy limits and the well-recognised high spatial and temporal variability inherent in observed E. coli concentrations (Boehm, 2007; Rosenfeld et al., 2006; Whitman and Nevers, 2004; Quilliam et al., 2011; Cui et al., 2013). Therefore the authors are of the view that beach managers should be judicious when interpreting results from such models for decisions regarding the public's use of bathing waters.

Finally, the revised Bathing Water Directive defines water quality in terms of both E. coli and IE, and therefore decisions for beach management such as the ones shown in Figure 2 would be typically based on both water quality parameters. However, measured and predicted IE concentrations for both Scenarios 1 and 2 in the current study were below the Sufficient standard values of the Bathing Water Directive (i.e., in the correct negatives category) and given therefore, that the inclusion of an IE analysis would not contribute to the objective of this paper, its presentation was not included.

\section{Conclusion}

Under the revised Bathing Water Directive (2006/7/EC), EU member states are obliged to maximise the protection of public health against faecal pollution at bathing waters through improved monitoring and management approaches. In Europe, the use of predictive models as beach management tools are less common than elsewhere in the world, despite the role they can play in the implementation of the revised EU Bathing Water Directive.

This study explores the potential use of a deterministic coastal water quality prediction model as a beach management tool for the improved protection of public health as required by Directive 
2006/7/EC. Such a tool provides water quality predictions well in advance of the occurrence of elevated FIB levels and this can inform beach managers in the decision making process on whether to prohibit bathing or advise the public not to bathe. The work assesses the efficacy of the tool in minimising the "errors" in beach management decisions. Such errors occur when the concentrations of predicted FIB are not equal to the actual concentrations and may result in either inadvertent exposure of the public to high concentrations of FIB or exclusion of swimmers from bathing water that meet acceptable standards under Directive 2006/7/EC.

Using a calibrated catchment-coastal model of the Dargle-Bray system, Co. Wicklow, Ireland, the study presented results of simulations that provided short-term and real-time predictions of E. coli at Bray beach. Two scenarios were studied: (i) Scenario 1, where rainfall forecasts from a meteorological source ( $\underline{\text { www.yr.no }}$ ) was used to drive the rainfall-runoff processes in the catchment component of the prediction tool, and (ii) Scenario 2, where the rainfall forecasts of Scenario 1 were improved by incorporating real-time rainfall data from within the catchment.

The RSR and d index of agreement values for days D-2 and D show that predictions of Scenario 2, the scenario with improved rainfall forecasts, offers a superior fit to observed $E$. coli concentrations than for Scenario 1. In addition, the analysis of the beach management decisions of the contingency table and metrics show that the real-time model has correctly predicted the compliance/ failures of Bray beach in meeting the Sufficient standard value of the revised Directive for $77 \%$ and $79 \%$ of the predictions of Scenarios 1 and 2 respectively. Relying on outputs from the prediction tool to support the beach management decision making for the investigated period from the $11^{\text {th }}$ August to the $5^{\text {th }}$ Sep, 2012 was shown to result in correct management decisions being made for Bray beach for 77$79 \%$ of the occasions. Conversely, the real-time component has produced data that would unnecessarily prohibit bathing for $4 \%$ of the predictions (type I errors) and would unnecessarily expose bathers to public health risks from poor bathing water quality (type II errors) for 19\% and 17\% of the predictions for Scenarios 1 and 2 respectively.

The results highlight the marginal superiority of Scenario 2, with the benefit of the inclusion of realtime rainfall data, in predicting bathing water quality at Bray beach. Nevertheless, the reasonable results for Scenario 1 indicate that the prediction tool may still produce acceptable predictions based on rainfall forecasts only. This may benefit catchment-coastal systems where limited or no real-time rainfall data is available.

The results provide support to the prediction tool for having the capacity to predict, with reasonable accuracy, the E. coli concentrations at Bray beach. However, inconsistencies between measured and predicted E. coli concentrations may still occur due to model accuracy limits and the inherent high spatial and temporal variability of measured E. coli concentrations. Therefore beach managers should 
be judicious when interpreting such results for decision making regarding an appropriate course of action for effective management of bathing water resources.

\section{Acknowledgements}

The work has been funded in part by the European Regional Development Fund (Interreg 4A: Ireland/Wales Programme 2007-2013), the Irish Environmental Protection Agency and the Department of Environment, Community and Local Government. Technical support on the use of the model was provided by DHI (UK and Denmark). The authors wish to acknowledge the help and information provided by Irish EPA, Bray Town Council, Wicklow County Council, and the staff of Shanganagh Wastewater Treatment works.

Figure 1: Study area. (a) Location of sensors within the Dargle catchment, (b) Inflow of the Dargle River to Bray Harbour.

Figure 2: Management outcomes: performance of Scenarios 1 and 2 in predicting the exceedence/ compliance of $E$. coli concentrations with the Sufficient standard values of Directive 2006/6/EC.

Table 1: Revised Bathing Water Directive (2006/7/EC) classification category limits (cfu/100 ml) for intestinal enterococci (IE) and Escherichia coli (E. coli).

Table 2: Contingency table: Management errors, outcomes, and health risk implications using the model for the prediction of $E$. coli concentrations.

Table 3: Metrics of the contingency table (Bennett et al., 2013).

Table 4: Computed RSR and $d$ index for the assessment of the performance of the prediction tool in predicting E. coli concentrations.

Table 5: Computed metrics for the assessment of the performance of the prediction tool in predicting compliance/exceedence of the E. coli with the Sufficient standard values of Directive 2006/7/EC.

\section{References}

Bae, H.K., Olson, B.H., Hsu, K.L., Sorooshian, S., 2010. Classification and regression tree (CART) analysis for indicator bacterial concentration prediction for a California coastal area. Water Science \& Technology 61, 545-553. 
Bedri, Z., Corkery, A., O'Sullivan, J.J., Alvarez, M.X., Erichsen, A.C., Deering, L.A., Demeter, K., O'Hare, G.M.P., Meijer, W.G., Masterson, B., 2014. An integrated catchment-coastal modelling system for real-time water quality forecasts. Environmental Modelling \& Software 61, 458-476.

Bennett, N.D., Croke, B.F.W., Guariso, G., Guillaume, J.H.A., Hamilton, S.H., Jakeman, A.J., Marsili-Libelli, S., Newham, L.T.H., Norton, J.P., Perrin, C., Pierce, S.A., Robson, B., Seppelt, R., Voinov, A.A., Fath, B.D., Andreassian, V., 2013. Characterising performance of environmental models. Environmental Modelling \& Software 40, 1-20.

Boehm, A.B., 2007. Enterococci concentrations in diverse coastal environments exhibit extreme variability. Environmental Science \& Technology 41, 8227-8232.

Bruen, M.P., Chawla, R., Crowther, J., Francis, C.A., Kay, D., Masterson, B.F., O’Connor, P.E., Parmentier, B., Stokes, J., Thorp, M.B., Watkins, J., Wyer, M.D., 2001. Achieving EU standards in recreational waters, in: Maritime Ireland/Wales INTERREG. Report No. 6. The Marine Institute, Dublin, Ireland.

CEC, 1976. Council of the European Communities Directive of 8th December 1975 concerning the quality of bathing water (76/160/EEC). Official Journal of European Communications L31, 1-7.

Cui, H., Yang, K., Pagaling, E., Yan, T., 2013. Spatial and temporal variation in Enterococci abundance and its relationship to the microbial community in Hawaii Beach sand and water. Applied \& Environmental Microbiology 79, 3601-3609.

DHI, 2013a. MIKE11, A modelling system for rivers and channels. Reference manual. DHI Group Horshølme, Denmark.

DHI, 2013b. MIKE 3 Flow Model FM. Hydrodynamic module - User guide. DHI Group Horshølme, Denmark.

E.C., 2006. European Council Directive 2006/7/EC of 15 February 2006 concerning the management of bathing water quality and repealing Directive 76/160/EEC. Official Journal of European Communications L 64/37.

EPA, 2013. Information note on short term pollution (STP) events specified in the 2008 Bathing Water Quality Regulations (SI NO. 79 of 2008). OEA Bathing Water Unit, Environmental Protection Agency, Wexford, Ireland.

ETC, 2012. Issues Paper on monitoring and assessment under the 2006 Bathing Water Directive. European Topic Centre/ Inland Coastal, Marine waters. Accessed from: http://www.eea.europa.eu/. 
Fleisher, J.M., Kay, D., Salmon, R.L., Jones, F., Wyer, M.D., Godfree, A.F., 1996. Marine waters contaminated with domestic sewage: nonenteric illnesses associated with bather exposure in the United Kingdom. American Journal of Public Health 86, 1228-1234.

Francy, D.S., 2009. Use of predictive models and rapid methods to now-cast bacteria levels at coastal beaches. Aquatic Ecosystem Health \& Management 12, 177-182.

Frick, W.E., Ge, Z., Zepp, R.G., 2008. Now-casting and forecasting concentrations of biological contaminants at beaches: a feasibility and case study. Environmental Science \& Technology 42, 48184824.

Haile, R.W., Witte, J.S., Gold, M., Ron, C., McGee, C., Millikan, R.C., Glasser, A., Harawa, N., Ervin, C., Harmon, P., Harper, J., Dermand, J., Alamillo, J., Barrett, K., Nides, M., Wang, G.-Y., 1999. The health effects of swimming in ocean water contaminated by storm drain runoff. Epidemiology 10, 355-363.

He, L.-M., He, Z.-L., 2008. Water quality prediction of marine recreational beaches receiving watershed baseflow and stormwater runoff in southern California, USA. Water Research 42, 25632573.

Hou, D., Rabinovici, S.J.M., Boehm, A.B., 2006. Enterococci predictions from partial least squares regression models in conjunction with a single-sample standard to improve the efficacy of beach management advisories. Environmental Science \& Technology 40, 1737-1743.

ISO, 2000. Water quality - detection and enumeration of Escherichia coli and coliform bacteria. Part 1: Membrane filtration method. ISO 9308-1:2000(E). International Organization for Standardization, Geneva, Switzerland.

Mansfield, M., 1992. Dublin Bay water quality management plan: Field studies of currents and dispersion. Technical Report 3. Environmental Research Unit, Dublin, Ireland.

Manzato, A., 2007. Sounding-derived indices for neural network based short-term thunderstorm and rainfall forecasts. Atmospheric Research 83, 349-365.

McPhail, C.D., Stidson, R.T., 2009. Bathing water signage and predictive water quality models in Scotland. Aquatic Ecosystem Health \& Management 12, 183-186.

Moriasi, D.N., Arnold, J.G., Liew, M.W.V., Bingnew, R.L., Harmel, R.D., Veith, T.L., 2007. Model evaluation guidelines for systematic quantification of accuracy in watershed simulations. Transactions of the American Society of Agricultural and Biological Engineers 50, 885-900. 
Nevers, M.B., Whitman, R.L., 2005. Now-cast modeling of Escherichia coli concentrations at multiple urban beaches of southern Lake Michigan. Water Research 39, 5250-5260.

Nevers, M.B., Whitman, R.L., 2011. Efficacy of monitoring and empirical predictive modeling at improving public health protection at Chicago beaches. Water Research 45, 1659-1668.

Olyphant, G., Whitman, R., 2004. Elements of a predictive model for determining beach closures on a real-time basis: the case of 63rd Street Beach, Chicago. Environmental Monitoring \& Assessment 98, 175-190.

Parkhurst, D.F., Brenner, K.P., Dufour, A.P., Wymer, L.J., 2005. Indicator bacteria at five swimming beaches - analysis using random forests. Water Research 39, 1354-1360.

Quilliam, R., Clements, K., Duce, C., Cottrill, S., Malham, S., Jones, D., 2011. Spatial variation of waterborne Escherichia coli - implications for routine water quality monitoring. Journal of Water \& Health 9, 734-737.

Rosenfeld, L.K., McGee, C.D., Robertson, G.L., Noble, M.A., Jones, B.H., 2006. Temporal and spatial variability of fecal indicator bacteria in the surf zone off Huntington Beach, CA. Marine Environmental Research 61, 471-493.

Stidson, R.T., Gray, C.A., McPhail, C.D., 2012. Development and use of modelling techniques for real-time bathing water quality predictions. Water \& Environment Journal 26, 7-18.

Thoe, W., Gold, M., Griesbach, A., Grimmer, M., Taggart, M.L., Boehm, A.B., 2014. Predicting water quality at Santa Monica Beach: evaluation of five different models for public notification of unsafe swimming conditions. Water Research 67, 105-117.

Thoe, W., Wong, S.H.C., Choi, K.W., Lee, J.H.W., 2012. Daily prediction of marine beach water quality in Hong Kong. Journal of Hydro-environment Research 6, 164-180.

USEPA, 2010a. Predictive tools for beach notification. Volume I: Review and technical protocol. U.S. Environmental Protection Agency EPA-823-R-10-003.

USEPA, 2010b. Predictive modeling at beaches. Volume II: Predictive tools for beach notification. U.S. Environmental Protection Agency EPA-600-R-10-176.

Wade, T.J., Calderon, R.L., Brenner, K.P., Sams, E., Beach, M., Haugland, R., Wymer, L., Dufour, A.P., 2008. High sensitivity of children to swimming-associated gastrointestinal illness: results using a rapid assay of recreational water quality. Epidemiology 19, 375-383. 
Whitman, R.L., Nevers, M.B., 2004. Escherichia coli sampling reliability at a frequently closed Chicago Beach: monitoring and management implications. Environmental Science \& Technology 38, 4241-4246.

WHO, 2003. Guidelines for safe recreational water environments. In: Coastal and Freshwaters, vol. 1. World Health Organization, Geneva, Switzerland.

Willmott, C.J., 1981. On the validation of models. Physical Geography 2, 184-194.

Zhang, Z., Deng, Z., Rusch, K.A., 2012. Development of predictive models for determining enterococci levels at Gulf Coast beaches. Water Research 46, 465-474. 


\section{Figure 1}

Click here to download Figure: Figure1.studyarea.eps

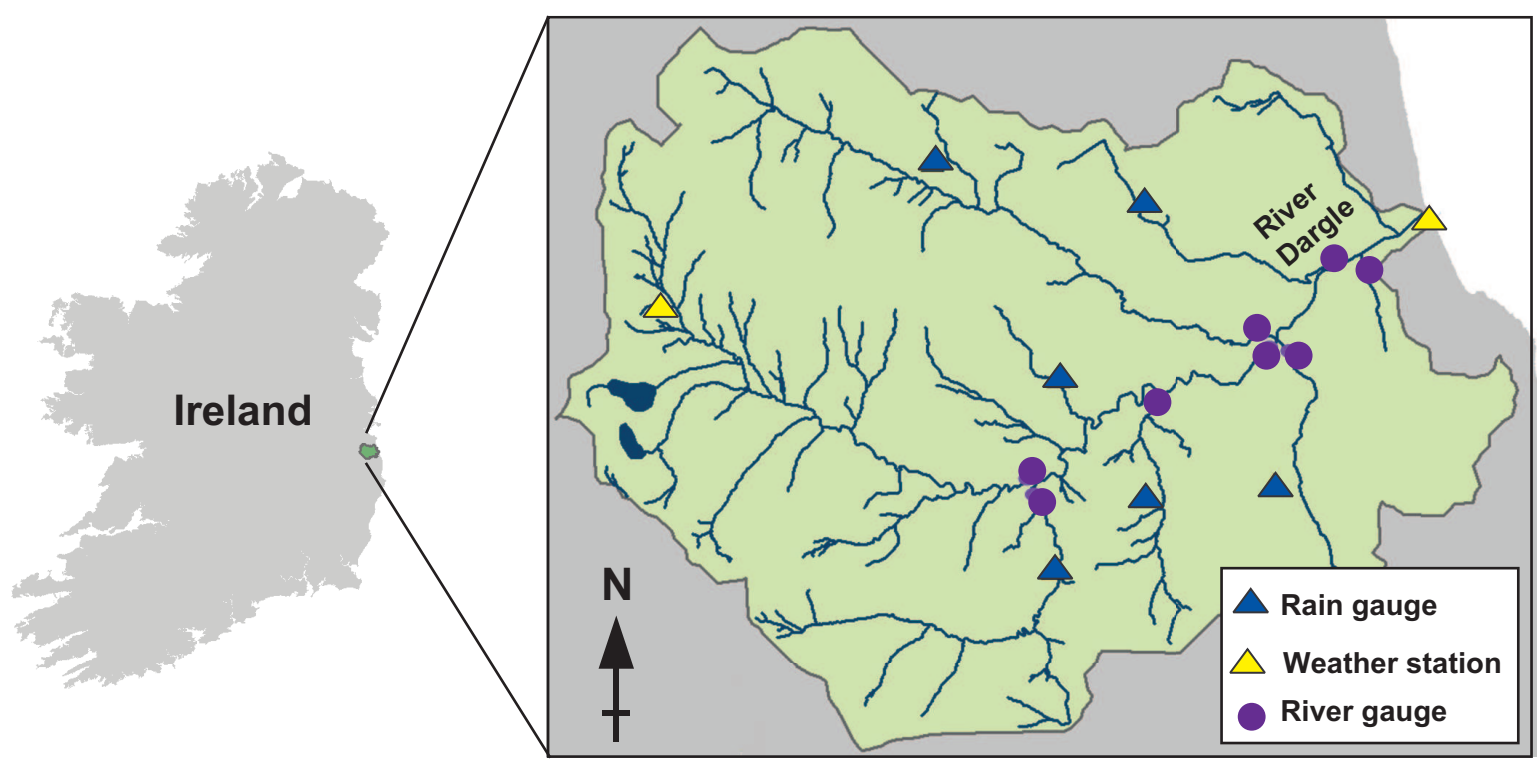

(a) Dargle catchment: Location of sensors

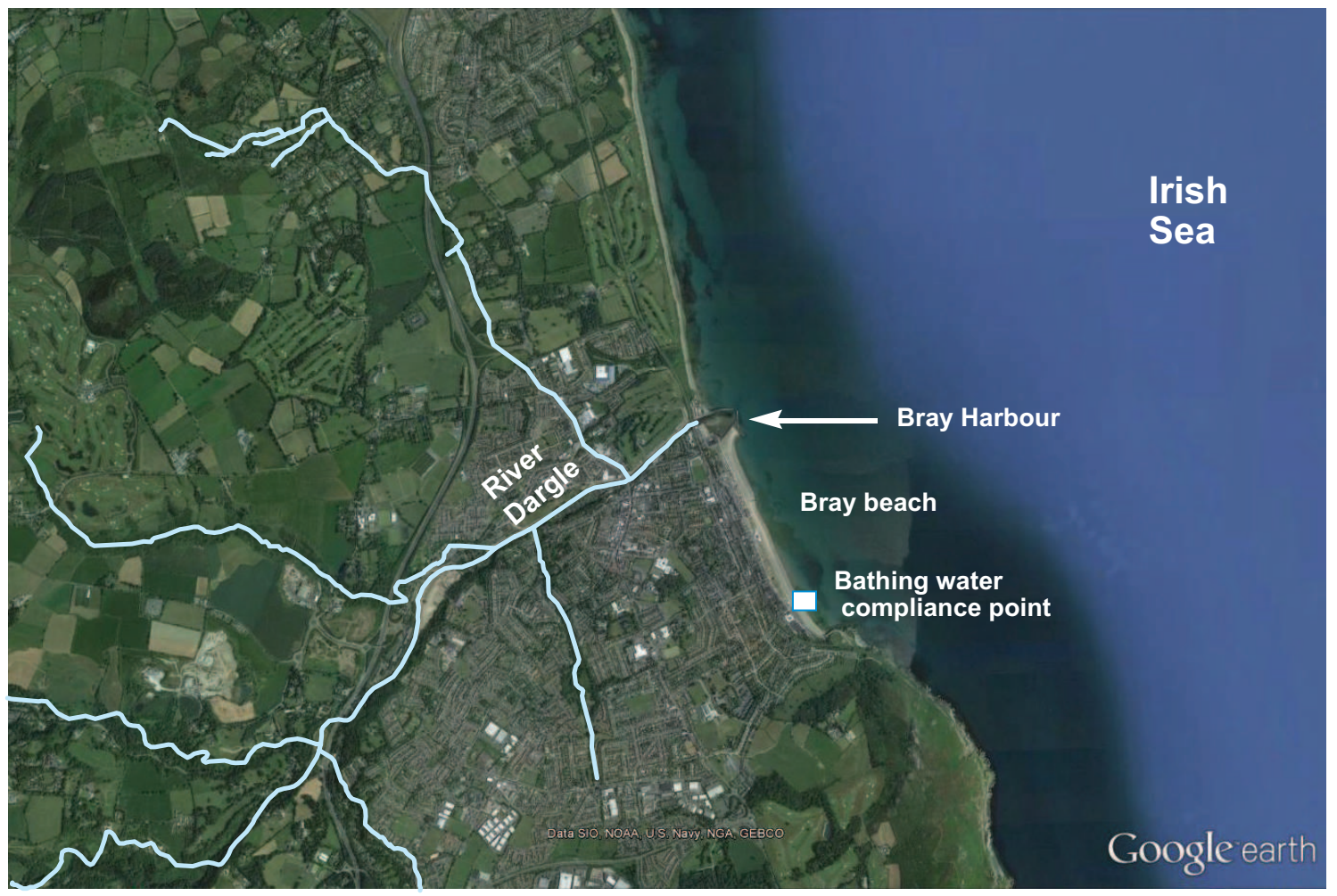

(b) Inflow of Dargle River to Bray Harbour 


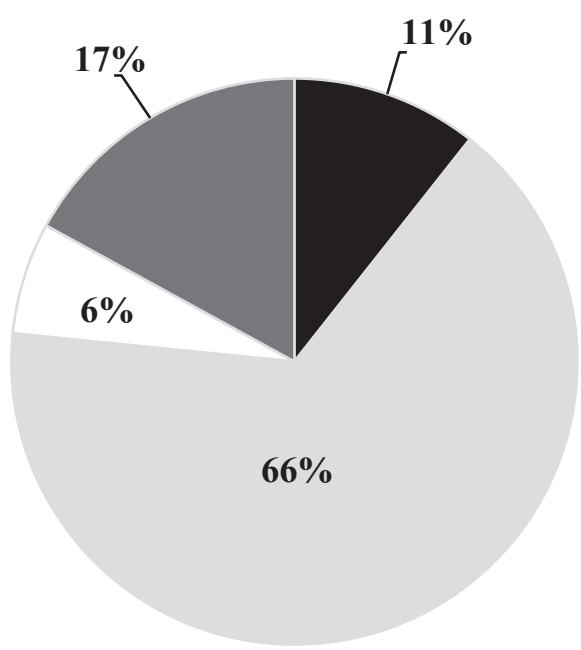

Forecasting day: D-2

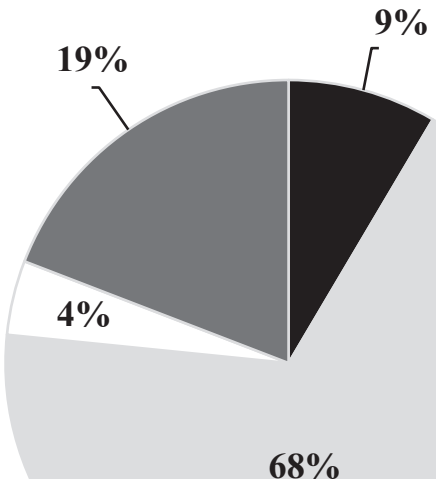

Forecasting day: D

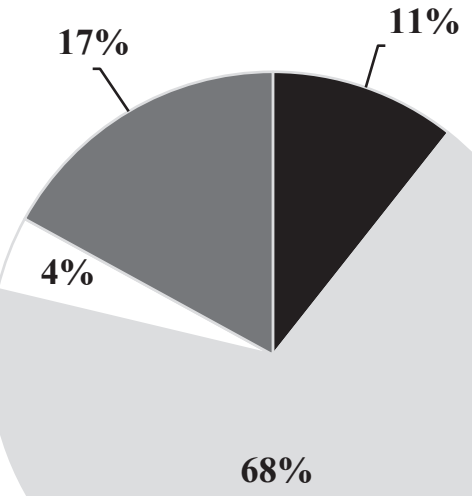

Forecasting day: D
Forecasting day: D-2

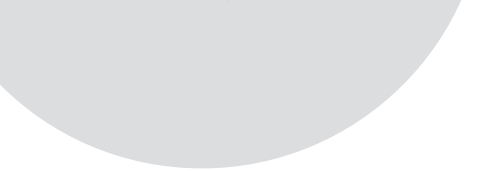

(a) Scenario 1: Forecasts only

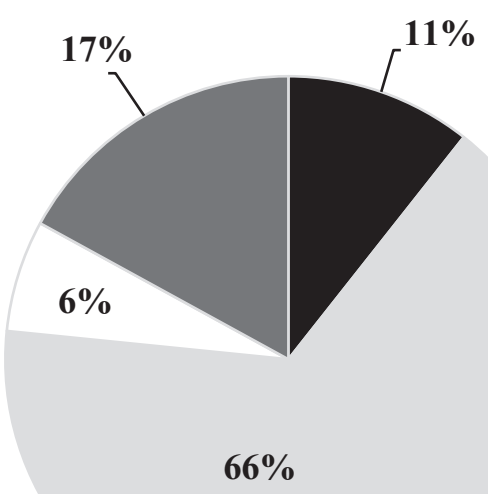

(b) Scenario 2: Improved forecasts
Correct action taken

$\square$ Correct no action

$\square$ Type I error

$\square$ Type II error 
Table 1. Revised Bathing Water Directive (2006/7/EC) classification category limits (cfu/100 ml) for intestinal enterococci (IE) and Escherichia coli (E. coli)

\begin{tabular}{|l|c|c|c|}
\hline \multirow{2}{*}{ Parameter } & \multicolumn{3}{|c|}{ Classification } \\
\cline { 2 - 4 } & Excellent & Good & Sufficient \\
\hline E. coli & $250^{\mathrm{a}}$ & $500^{\mathrm{a}}$ & $500^{\mathrm{b}}$ \\
\hline IE & $100^{\mathrm{a}}$ & $200^{\mathrm{a}}$ & $185^{\mathrm{b}}$ \\
\hline
\end{tabular}

a: based on $95^{\text {th }}$ percentiles, b: based on $90^{\text {th }}$ percentiles. 
Table 2: Contigency Table: Management errors, outcomes, and health risk implications using the model for the prediction of $E$. coli concentrations.

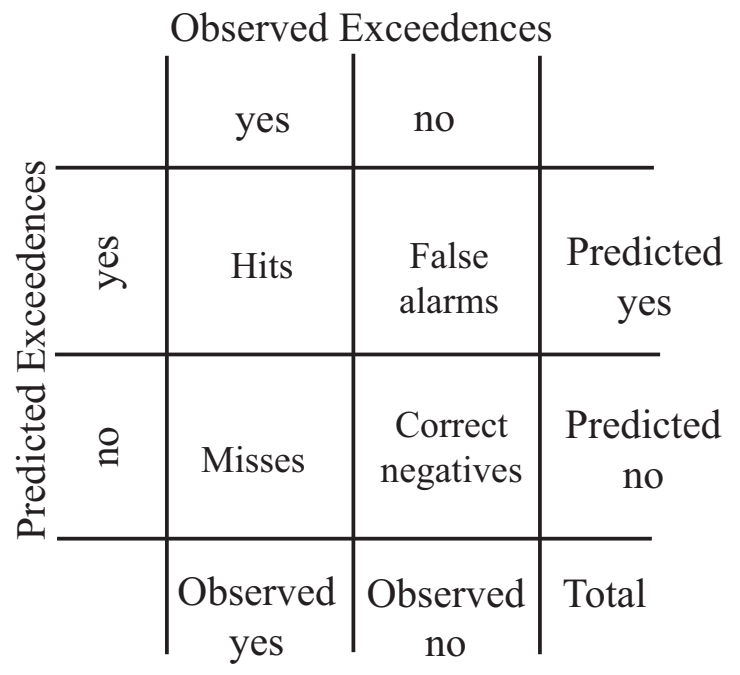

(a) Contingency Table

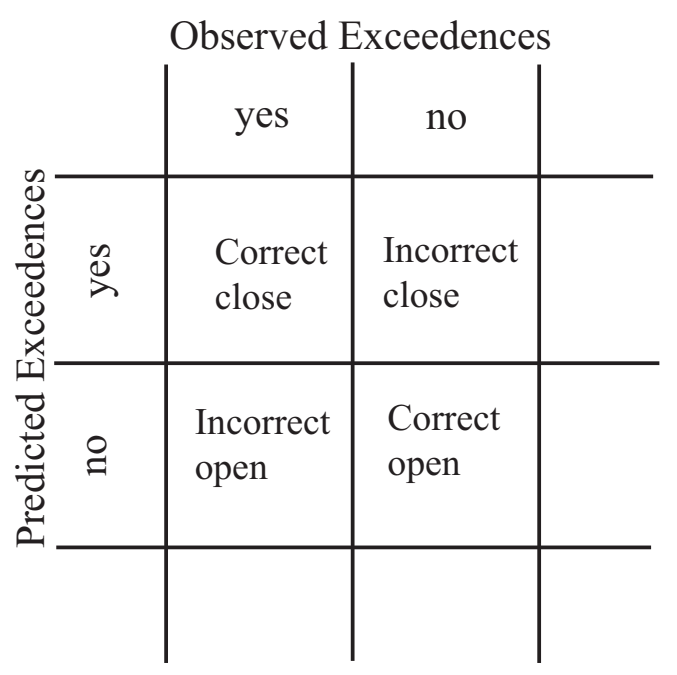

(c) Management outcomes

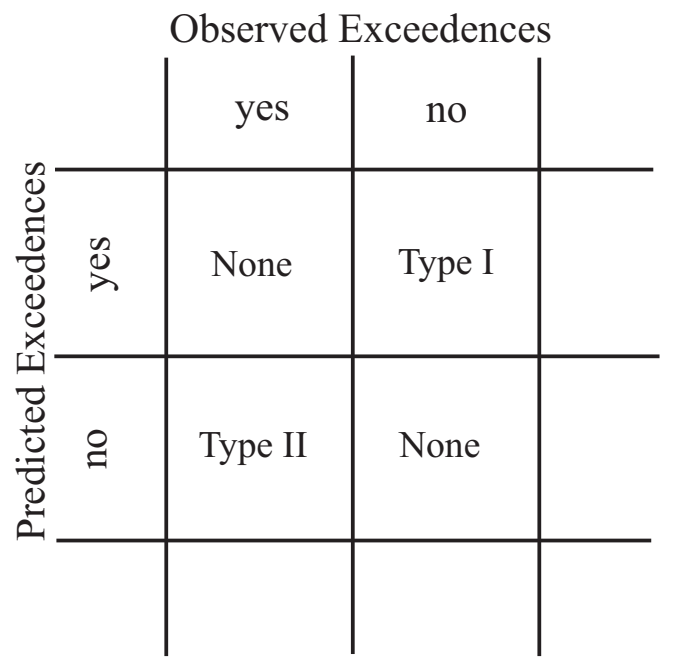

(b) Management error

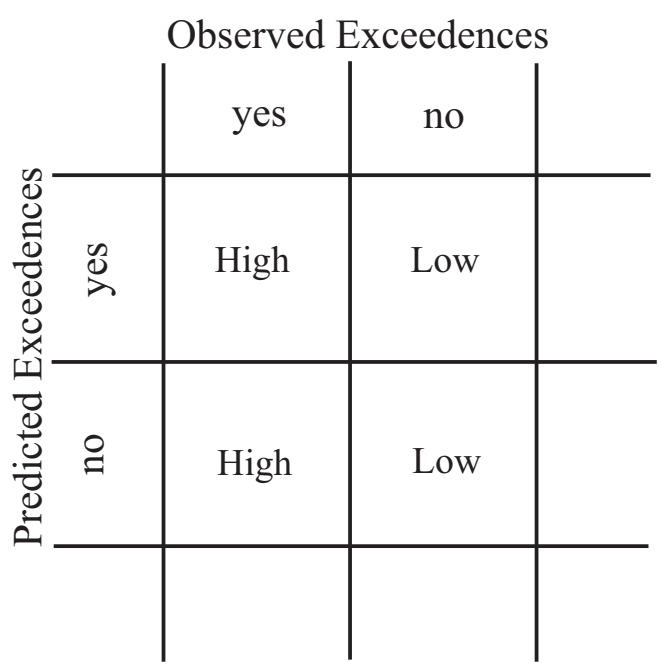

(d) Possible health risk 
Table 3: Metrics of the contingency table (Bennett et al., 2013).

\begin{tabular}{|l|c|c|c|}
\hline Metric & Formula & Range of values & Ideal value \\
\hline Accuracy & $\frac{\text { Hits }+ \text { Correct negatives }}{\text { Total }}$ & $0-1$ & 1 \\
\hline Bias score & $\frac{\text { Hits }+ \text { False alarms }}{\text { Hits }+ \text { Misses }}$ & $0-\infty$ & 1 \\
\hline Hit rate & $\frac{\text { Hits }}{\text { Hits }+ \text { Misses }}$ & $0-1$ & 0 \\
\hline False alarm rate & False alarms + Correct negatives & $0-1$ & 0 \\
\hline False alarm ratio & $\frac{\text { False alarms }}{\text { Hits }+ \text { False alarms }}$ & $0-1$ & 1 \\
\hline Success index & $\frac{1}{2}\left[\frac{\text { Hits }}{\left.\text { Hits }+ \text { Misses }+\frac{\text { Correct negatives }}{\text { Thotal }}\right]}\right.$ & $0-1$ & 1 \\
\hline Threat score & $\frac{\text { Hits }}{\text { Hits }+ \text { Misses }+ \text { False alarms }}$ & $0-1$ & \\
\hline
\end{tabular}


Table 4: Computed RSR and $d$ index for the assessment of the performance of the prediction tool in predicting E. coli concentrations.

\begin{tabular}{|l|c|c|c|c|}
\hline \multirow{2}{*}{ Day } & \multicolumn{4}{|c|}{ Forecasting day } \\
\cline { 2 - 5 } & \multicolumn{2}{|c|}{ D-2 } & \multicolumn{2}{c|}{ D } \\
\hline Metric & Scenario 1 & Scenario 2 & Scenario 1 & Scenario 2 \\
\hline RSR & 1.23 & 1.17 & 1.04 & 0.99 \\
\hline$d$ index & 0.61 & 0.62 & 0.66 & 0.67 \\
\hline
\end{tabular}


Table 5: Computed metrics for the assessment of the performance of the prediction tool in predicting compliance/exceedence of the Sufficient E. coli standard values of Directive 2006/7/EC.

\begin{tabular}{|c|c|c|c|c|}
\hline \multicolumn{4}{|c|}{ Sufficient Standard } \\
\hline \multirow{2}{*}{ Scenario } & \multicolumn{2}{|c|}{ Forecasting day: D-2 } & \multicolumn{2}{c|}{ Forecasting day: D } \\
\cline { 2 - 5 } & Scenario 1 & Scenario 2 & Scenario 1 & Scenario 2 \\
\hline Accuracy & 0.77 & 0.77 & 0.77 & 0.79 \\
\hline Hit rate & 0.38 & 0.38 & 0.31 & 0.38 \\
\hline False alarm rate & 0.09 & 0.09 & 0.06 & 0.06 \\
\hline False alarm ratio & 0.38 & 0.38 & 0.33 & 0.29 \\
\hline Success index & 0.52 & 0.52 & 0.49 & 0.53 \\
\hline
\end{tabular}

